\title{
Follicular growth after xenotransplantation of cryopreserved/thawed human ovarian tissue in SCID mice: dynamics and molecular aspects
}

\author{
Sarrah Ayuandari ${ }^{1,2} \cdot$ Katharina Winkler-Crepaz $^{1}$ - Monika Paulitsch ${ }^{1,3}$. \\ Cora Wagner $^{1}$ - Claudia Zavadil ${ }^{4}$. Claudia Manzl ${ }^{4}$. Stephanie C. Ziehr ${ }^{1,5}$. \\ Ludwig Wildt ${ }^{1} \cdot$ Susanne Hofer-Tollinger ${ }^{1}$
}

Received: 10 February 2016 / Accepted: 1 July 2016 / Published online: 27 July 2016

(C) The Author(s) 2016. This article is published with open access at Springerlink.com

\begin{abstract}
Purpose To study the influence of xenotransplantation on follicular recruitment and growth in cryopreserved/thawed human ovarian tissue.

Method Two 3-mm pieces of cryopreserved/thawed human ovarian tissue obtained from female cancer patients $(n=11)$ were xenotransplanted into a subcutaneous neck pouch of 6week-old ovarectomized SCID mice $(n=33)$ for $4(n=18)$ and $12(n=15)$ weeks.

Result Thirty-two out of 33 mice survived the entire observation periods. Graft recovery rate was $95.58 \%$ (65 of 68 grafts).

Capsule The higher proportion of growing follicles compared to resting follicles observed after xenotransplantation is most likely due to downregulation of PTEN gene expression followed by acceleration of follicular recruitment.
\end{abstract}

Electronic supplementary material The online version of this article (doi:10.1007/s10815-016-0769-2) contains supplementary material, which is available to authorized users.

Katharina Winkler-Crepaz

katharina.winkler@i-med.ac.at

Sarrah Ayuandari

sarrah.ayuandari@student.i-med.ac.at

Monika Paulitsch

monika.paulitsch@uibk.ac.at

Cora Wagner

cora.wagner@student.i-med.ac.at

Claudia Zavadil

claudia.zavadil@i-med.ac.at

Claudia Manzl

claudia.manzl@i-med.ac.at

Stephanie C. Ziehr

stephanie.ziehr@ivf-muenchen.com
The percentages of primordial follicles after 4 weeks $(P<0.001)$ and 12 weeks $(P=0.009)$ of grafting were significantly lower in comparison to pregraft controls. The percentage of secondary follicle was significantly higher after 4 weeks of grafting $(P=0.018)$ and after 12 weeks $(P=0.001)$ of grafting in comparison to pregraft controls. Ki67 immunohistochemistry showed that proliferative follicles were significantly higher after 4 and 12 weeks of grafting compared to pregraft controls $(P<0.001)$. All follicles analyzed by TUNEL staining appeared healthy after xenotransplantation. The expression level of PTEN was reduced by 2.47 -fold after 4 weeks of
Ludwig Wildt

ludwig.wildt@i-med.ac.at

Susanne Hofer-Tollinger

susanne.hofer@i-med.ac.at

1 Department of Gynecological Endocrinology and Reproductive Medicine, Medical University of Innsbruck, Anichstr. 35, 6020 Innsbruck, Austria

2 Department of Obstetrics and Gynecology, Faculty of Medicine, Gadjah Mada University, Jl. Farmako, 55281 Yogyakarta, Indonesia

3 Institute of Zoology, University of Innsbruck, Technikerstr. 25, 6020 Innsbruck, Austria

4 Department of Pathology, Medical University of Innsbruck, Müllerstr. 44, 6020 Innsbruck, Austria

5 A.R.T. Bogenhausen, Prinzregentenstr. 69, 81675 Munich, Germany 
xenotransplantation, and this result was significant when $2^{-\Delta \mathrm{Ct}}$ were analyzed $(P=0.042)$.

Conclusion The higher proportion of growing follicles compared to resting follicles observed after xenotransplantation is most likely due to downregulation of PTEN gene expression followed by acceleration of follicular recruitment.

Keywords Fertility preservation - Human ovarian tissue xenotransplantation - Human ovarian tissue cryopreservation - Follicular recruitment . PTEN

\section{Introduction}

The numbers of long-term cancer survivors are steadily increasing during the last decades leading to an actual 5-year survival rate for children of $79 \%$ [1]. Several factors such as early cancer detection, advanced diagnostic tools, and aggressive cancer therapies have been contributing to this improvement. Therefore, due to the increasing life expectancy in cancer patients, the late side effects caused by high dose chemotherapies and radiotherapies are currently gaining more attention. One of the common and serious long-term side effects related to cancer therapy in female patients is premature ovarian failure (POF). Chemotherapeutic agents and irradiation are known to induce POF through destruction of ovarian follicular reserve by different mechanisms depending on the age of the patients, as well as on the type and the dose of cytotoxic agents [2-6].

To overcome this problem, several multidisciplinary strategies have been established to preserve female fertility [7-11]. One of the important developments in fertility preservation is ovarian tissue cryopreservation and autotransplantation. This method might be the only available method for prepubertal girls. Furthermore, it can be offered to patients immediately without delay in cancer therapy [9]. So far, there are more than 60 live births reported worldwide after autotransplantation of cryopreserved/thawed human ovarian tissue [12-22]. Data from three fertility preservation centers showed that endocrine ovarian function can be restored in $93 \%$ of patients after autotransplantation [23]. Pregnancy rates after 111 cases of ovarian tissue autotransplantation in 5 fertility preservation centers were $29 \%$ [24]. However, clinical data showed decreased ovarian reserve and low response to ovarian stimulation in patients after ovarian tissue autotransplantation [25, 26]. This decreased ovarian reserve after transplantation was proven by the low concentrations of anti-Mullerian hormone $(\mathrm{AMH})$ and inhibin $\mathrm{B}$ as well as high levels of folliclestimulating hormone (FSH) [25-27]. This indicates that further studies are needed to improve the outcome of ovarian tissue cryopreservation followed by autotransplantation.

One accepted experimental approach to evaluate functionality of cryopreserved human ovarian tissue is xenotransplantation into severe combined immunodeficient (SCID) mice
[28]. Several studies showed a considerable decline in follicular density and an increase of follicular growth after xenotransplantation [29-32]. However, the mechanisms behind this rapid follicular recruitment and subsequent follicular loss after xenotransplantation are still unclear. Especially molecules regulating cell growth and organ size are currently being investigated as published by Kawamura et al. [14]. Furthermore, Roness et al. [33] hypothesized that the increase of follicular growth might be caused by disruption of follicular growth regulation leading to "ovarian follicle burnout." The same authors observed this phenomenon in a mouse model, after administration of the gonadotoxic agent cyclophosphamide as well as after xenotransplantation of untreated bovine ovarian tissue [34, 35]. In addition to that, Silber et al. [20] observed an "over-recruitment" of resting follicles after ovarian tissue transplantation indicated by the increase of AMH to above normal levels in the recipient compared to the donor.

One of the important pathways for maintenance of follicular dormancy is the phosphoinositide 3-kinase (PI3K)/phosphatase and tensin homolog deleted on chromosome 10 (PTEN)/protein kinase B (Akt) pathway [36-38]. PTEN has been shown to be an important inhibitor of follicular growth initiation [39]. Oocyte-specific deletion of PTEN in mice led to over-activation of primordial follicles and subsequently to POF $[39,40]$. In addition, it has been shown that PTEN inhibitors can cause follicular activation of murine follicles in vivo and of human follicles in vitro [41-43].

The aim of this study was to evaluate the mechanisms involved in follicular recruitment after xenotransplantation of human ovarian tissue in SCID mice and to investigate the impact of transplantation on follicular growth and depletion.

\section{Materials and methods}

\section{Ethical approval}

The use of human ovarian tissue samples in this study was approved by the Ethical Committee of the Medical University of Innsbruck. The animal experimentation in this study was performed under the approval from the Federal Ministry of Science and Research of Austria.

\section{Human ovarian tissue}

Human ovarian tissue samples used in this study were obtained from 11 cancer patients with informed consent. The age of the patients at the time of ovarian tissue cryopreservation ranged from 20 to 39 years (mean age 27.0 years). AMH was determined with a commercially available ELISA kit (AMH Gen II ELISA, Beckman Coulter, Germany) before laparoscopic retrieval of ovarian tissue in all patients except one. Patient characteristics are presented in Table 1. 
Table 1 Patients' characteristics

\begin{tabular}{lllll}
\hline No. & Diagnosis & $\begin{array}{l}\text { Age at } \\
\text { cryopreservation }\end{array}$ & $\begin{array}{l}\text { AMH prior } \\
\text { to surgery } \\
(\mu \mathrm{g} / \mathrm{l})\end{array}$ & $\begin{array}{l}\text { Chemotherapy } \\
\text { prior to surgery } \\
(\mathrm{Y} / \mathrm{N})\end{array}$ \\
\hline 1 & Morbus Hodgkin & 26 & 1.06 & $\mathrm{~N}$ \\
2 & Breast Cancer & 33 & 2.66 & $\mathrm{~N}$ \\
3 & Morbus Hodgkin & 22 & Not applicable & $\mathrm{N}$ \\
4 & Breast cancer & 33 & 0.86 & $\mathrm{~N}$ \\
5 & Breast cancer & 27 & 2.14 & $\mathrm{~N}$ \\
6 & Morbus Hodgkin & 27 & 1.62 & $\mathrm{Y}$ \\
7 & Breast Cancer & 39 & $<0.17$ & $\mathrm{~N}$ \\
8 & ALL & 20 & 2.66 & $\mathrm{Y}$ \\
9 & B-NHL & 22 & 0.33 & $\mathrm{Y}$ \\
10 & AML & 23 & $<0.17$ & $\mathrm{Y}$ \\
11 & NHL & 25 & 2.70 & $\mathrm{~N}$ \\
\hline
\end{tabular}

In 10 out of 11 patients, AMH levels were measured before the laparoscopical retrieval of ovarian tissue for cryopreservation. Seven patients did not receive chemotherapy before ovarian tissue cryopreservation and four patients received chemotherapy before ovarian tissue cryopreservation. In one patient ${ }^{\mathrm{a}}$, AMH level $(<0.17 \mu \mathrm{g} / \mathrm{l})$ was determined after the surgery and after the first cycle of chemotherapy

\section{Animals}

Female CB17/lcrHanHsd SCID mice were purchased from Harlan Laboratories, Italy, and delivered at 5 weeks of age. They were housed in a temperature- and light-controlled environment $\left(22{ }^{\circ} \mathrm{C}\right.$ and 12 -h light/12-h dark) in individually ventilated cages (IVC) with high-efficiency particulate air filters, at the animal care facility of the Medical University of Innsbruck. Animals were supplied with water and food ad libidum, and a maximum of six animals were housed per cage. Animals were allowed to acclimatize for 1 week.

All of the procedures related to the animals were performed under a laminar flow-hood. Thirty-three 6-week-old mice were used in this study. Five independent repeats of the complete experiment were carried out.

\section{Collection of human ovarian tissue}

Human ovarian tissue samples were laparoscopically retrieved and transferred to the laboratory of the Department of Gynecological Endocrinology and Reproductive Medicine, Medical University of Innsbruck, in Leibovitz medium (L-15, Invitrogen, Germany) within a 50-ml polystyrene conical tube (BD Falcon, BD Biosciences, Austria).

\section{Human ovarian tissue cryopreservation}

Cortical strips from human ovarian tissue samples $(\sim 10 \times 5 \times$ $2 \mathrm{~mm}$ ) were prepared under sterile conditions in Leibovitz medium. The cryopreservation procedure was performed using a slow-freezing protocol. Ovarian tissue samples were transferred to $2.0 \mathrm{ml}$ cryovials (Nunc, Germany) containing $1.7 \mathrm{ml}$ of cryopreservation medium (OvarStore, Gynemed,
Germany) and placed into an automated, computer-controlled freezing system (IceCube 14S, Sy-Lab, Austria). The initial cooling rate was $-2{ }^{\circ} \mathrm{C} / \mathrm{min}$ to $-7{ }^{\circ} \mathrm{C}$. At this temperature, manual seeding was performed. After keeping the tissue for $10 \mathrm{~min}$ at this temperature, cooling was continued at the rate of $-0.3{ }^{\circ} \mathrm{C} / \mathrm{min}$ until $-65^{\circ} \mathrm{C}$ for approximately $220 \mathrm{~min}$. Then cryovials were plunged into liquid nitrogen for storage.

\section{Human ovarian tissue thawing and preparation}

Under aseptic conditions, cryovials were placed at room temperature for $30 \mathrm{~s}$, and then transferred to a $37{ }^{\circ} \mathrm{C}$ water bath for $130 \mathrm{~s}$. Afterwards, the tissue samples were washed stepwise in medium containing DPBS (Sigma-Aldrich, Austria), gentamicin (Sigma-Aldrich, Austria), serum substitute supplements (Irvine Scientific, Austria), and decreasing sucrose concentrations (MP Biomedicals, Austria). The last washing step was performed in G-MOPS plus medium (Vitrolife, Austria). Thawed cortical strips were then dissected into 3-mm biopsies using standardized biopsy punches and immediately transported to the animal facility of the Medical University of Innsbruck within 50-ml falcon tubes containing $5 \mathrm{ml}$ prewarmed G-MOPS medium at $37{ }^{\circ} \mathrm{C}$.

\section{Xenotransplantation procedure}

Mice were anesthetized with $0.1 \mathrm{mg} / \mathrm{g}$ body weight ketamine hydrochloride (Ketasol, Gräub, Ogris Pharma, Austria) and $0.015 \mathrm{mg} / \mathrm{g}$ body weight of xylazine (Xylasol, Ani Medica Ogris Pharma, Austria) intraperitoneally [44]. The average body weight was $16.66 \mathrm{~g}$ and ranged from 14.50 to $18.40 \mathrm{~g}$. The surgery was performed on a $37^{\circ} \mathrm{C}$ warming plate for animal surgery (Vettech, UK). The eyes of the mice were 
protected with an eye protection gel (Siccaforte, Agepha Pharmaceutical, Austria). Bilateral ovarectomy was performed via a dorsomedian incision. Excised mouse ovaries were examined under a stereomicroscope (MZ6, Leica, Austria) to ensure complete ovarectomy. After ovarectomy, two 3-mm thawed human ovarian tissue pieces were xenotransplanted into a subcutaneous neck-pouch and the grafts were fixed with two 6/0 nylon sutures (Prolene, Ethicon, Johnson \& Johnson Medical Company, Austria). The peritoneum and skin incisions were closed with a $6 / 0$ nylon suture. Post-operative analgesia was assured by adding $25 \mu \mathrm{g}$ tramadol (Tramabene, Ratiopharm, Germany) per milliliter of drinking water. After grafting, the SCID mice were randomized to be observed for either for $4(n=18)$ or $12(n=$ 15 ) weeks. At the end of each observation period, the animals were sacrificed. The grafts were recovered and immediately fixed in $3.6 \%$ formalin. Ovarian tissue samples directly after thawing served as pregraft controls.

All procedures were carried out under a laminar flow hood in order to maintain sterile conditions.

\section{Follicle counting}

Grafts were fixed in formalin and embedded in paraffin for histological assessment. The paraffin blocks were cut into serial sections of 3-5 $\mu \mathrm{m}$. Every 12 th section was stained with Hematoxylin and Eosin (H\&E) for follicle classification and counting [45]. The sections in between were used for immunohistochemistry and RNA isolation. Follicular development was assessed by evaluating the follicular stages using a light microscope (BX 40; Olympus, Germany) as described by Myers et al. [46]. Briefly, a primordial follicle was defined by an oocyte surrounded by one layer of flattened pregranulosa cells, a primary follicle by an oocyte surrounded by one layer of cuboidal granulosa cells, and a secondary follicle by two or more layers of granulosa cells. An antral follicle was defined by antrum formation. In the case of intermediate stages between primordial and primary follicles, those follicles showing at least one cuboidal granulosa cell were classified as primary follicles. Only follicles with a visible nucleus in the oocyte were counted [47].

\section{Follicular proliferation}

Follicular proliferation was immunohistochemically evaluated by the detection of the expression of the Ki67-protein in granulosa cells. Ki67 is expressed during proliferative cell phases (G1, $\mathrm{S}, \mathrm{G} 2$, and mitosis), but not during the resting cell phase (G0).

Ki67 immunostaining was performed within an automated slide staining system (Benchmark Ultra, Ventana, USA) using a primary monoclonal rabbit antibody raised against human Ki67 (CONFIRM anti-Ki67, Ventana, Roche GmbH, USA), a secondary goat anti- rabbit antibody (HRP system, Ventana, Roche
$\mathrm{GmbH}, \mathrm{USA}$ ), and the 3,3-diaminobenzidine tetrahydrochloride (DAB) chromogen (ultraView DAB detection Kit, Ventana, Roche GmbH, USA). Nuclei were counterstained with hematoxylin. Human breast carcinoma tissue was used as positive control. Only sections where follicles were detected in the adjacent H\&Estained sections were analyzed.

Follicles with at least one granulosa cell stained positive with Ki67 were considered to be proliferative follicles [48].

\section{Follicular apoptosis}

To analyze apoptosis after xenotransplantation, terminal deoxynucleotidyl transferase-mediated dUTP nick end labeling (TUNEL) assay (DeadEndTM Colorimetric TUNEL System, Promega, Austria) was performed according to the manufacturer's instructions, with 3,3-diaminobenzidine tetrahydrochloride (DAB) as chromogen. Mayer's hemalaun solution (Merck Millipore, Germany) was used for counterstaining. Only sections where follicles were detected in the adjacent H\&E-stained sections were analyzed. The TUNEL staining results were evaluated by three independent observers.

Follicles consisting of $\geq 49 \%$ TUNEL positive granulosa cells as well as follicles containing a TUNEL positive oocyte were classified as atretic follicles [49]. Sections without transferase enzyme and human lymph node sections treated with DNAse served as negative and positive control, respectively.

\section{PI3K pathway analysis}

\section{PTEN gene expression}

Total ribonucleic acid (RNA) was isolated from 19 grafts bearing follicles obtained from 8 patients. Twenty sections per paraffin block were used for RNA isolation with RNEasy FFPE kit according to manufacturer's protocol (Qiagen, Germany). DNA digestion was performed using RNAse free DNAse (Promega, Austria).

RNA concentration was measured either with UVspectrophotometer (GeneQuant 1300 Spectrophotometer, GE Healthcare, Austria) or with a fluorescence staining kit (Quant-iT Ribogreen RNA reagent, Life Technologies, Germany). RNA was stored at $-80^{\circ} \mathrm{C}$. Reverse transcription was performed with $50 \mathrm{ng}$ of isolated RNA using the Omniscript reverse transcriptase (Qiagen, Germany) and random hexanucleotide primer (Carl Roth, Austria). Quantitative PCR (qPCR) was performed using the Maxima $\mathrm{SyBr}$ Green/ ROX qPCR master mix (Thermo Scientific, Austria). The following primers were used: PTEN (forward: PTEN, 5'TGACAATCATGTTGCAGCAATTC-3', reverse: 5'-CACC AGTTCGTCCCTTTCCA-3') as the target gene [50]. Actin (forward: 5'-ACT GGG ACG ACA TGG AGA AG-3', reverse: 5'-GGG GTG TTG AAG GTC TCA AA-3') was used as housekeeping gene. 
qPCR was performed in 96-well plates (Peqlab, Austria) using a BioRad iCycler (BioRad, Austria). The PCR profile was started with an initial incubation at $95^{\circ} \mathrm{C}$ for $10 \mathrm{~s}$, followed by 40 cycles with denaturation at $95^{\circ} \mathrm{C}$ for $5 \mathrm{~s}$, and annealing and extension at $60{ }^{\circ} \mathrm{C}$ for $45 \mathrm{~s}$. All qPCR measurements were performed in triplicates and samples without reverse transcriptase served as a negative control.

qPCR data were analyzed with iQ5 software (BioRad, Austria), and the efficiency of each qPCR run was evaluated with LinRegPCR data analysis program (version 2013.1; http://LinRegPCR.nl) [51, 52].

PTEN gene expression level was calculated by subtracting the actin CT values from PTEN CT values $(\Delta \mathrm{Ct})$. Relative quantitative analysis of PTEN gene expression was carried out using the $\Delta \Delta \mathrm{Ct}$ method [53]. Fold change difference of PTEN expression was determined as $2^{-(\Delta \mathrm{Ct} 4 \text { weeks }-\Delta \mathrm{Ct} \text { pregraft })}$.

\section{PTEN immunohistochemistry}

To analyze the protein expression of PTEN, immunohistochemistry was performed. Formalin-fixed and paraffinembedded tissue were cut into 3-5- $\mu \mathrm{m}$-thin sections and heated for $20 \mathrm{~min}$ at $70^{\circ} \mathrm{C}$. PTEN immunostaining was performed within an automated slide staining system (Benchmark Ultra, Ventana, USA) with a primary monoclonal rabbit anti-PTEN antibody (Clone D4.3, 1:250, Cell Signaling, USA), a secondary goat anti- rabbit antibody (HRP system, Ventana, Roche $\mathrm{GmbH}$, USA), and the DAB chromogen (ultraView DAB detection Kit, Ventana, Roche GmbH, USA). Nuclei were counterstained with hematoxylin. Human colon tissue was used as positive control and sections stained without any primary antibody was used as negative control.

\section{Statistics}

Statistical analysis was performed using the SPSS software package (version 20; SPSS, Inc., USA). All data are represented as mean $\pm \mathrm{SEM}$. The nonparametric Mann-Whitney $U$ test was performed to compare follicle counts. A paired-sample $t$ test was performed to compare PTEN gene expression. Immunohistochemical results from Ki67 were analyzed with chi-square test. Statistical significance was confirmed by $P$ values $<0.05$.

\section{Results}

\section{Macroscopic evaluation of the grafts}

Thirty-two of 33 mice $(96.97 \%)$ survived throughout the whole observation period. Sixty-five out of 68 grafts $(95.58 \%)$ were successfully recovered from all groups. Two grafts showed a macroscopically visible antral cavity after 12 weeks of grafting.

\section{Rapid follicular recruitment after xenotransplantation of cryopreserved/thawed human ovarian tissue}

\section{Follicle counting}

A total of 1014 follicles were counted within 58 biopsies. Twenty-six biopsies did not contain any follicles and were excluded from further calculations. Pregraft controls $(n=17)$ contained 669 follicles, 4-week grafts $(n=24)$ contained 183 follicles, and 12-week grafts $(n=17)$ contained 162 follicles. The percentage of primordial follicles after 4 weeks of grafting $(38.95 \pm 3.94 \%)$ was significantly lower in comparison to pregraft controls $(72.88 \pm 5.93 \%, P<0.001)$. The percentage of primordial follicles after 12 weeks of grafting $(37.42 \pm 5.83 \%)$ was also significantly lower $(P=0.009)$ compared to pregraft controls. The percentage of primary follicles was also significantly different after 4 weeks $(29.29 \pm$ $2.60 \%, P=0.009)$ compared to pregraft controls $(13.48 \pm$ $2.92 \%)$. However, the percentage of primary follicles was not significantly different after 12 weeks of grafting $(9.74 \%$ $\pm 2.22 \%)$ compared to pregraft control $(P=0.259)$. The percentage of secondary follicles was significantly increased after 4 weeks $(27.60 \pm 4.16 \%, P=0.018)$ and 12 weeks $(49.40 \pm$ $6.14 \%, P=0.001)$ of grafting compared to pregraft controls $(13.37 \pm 6.09 \%)$. There were two antral follicles observed in the pregraft control, one after 4 weeks of grafting, and two after 12 weeks of grafting. There was a significant difference in the percentage of primary follicles $(P=0.001)$ between the two observation periods after grafting (Fig. 1).

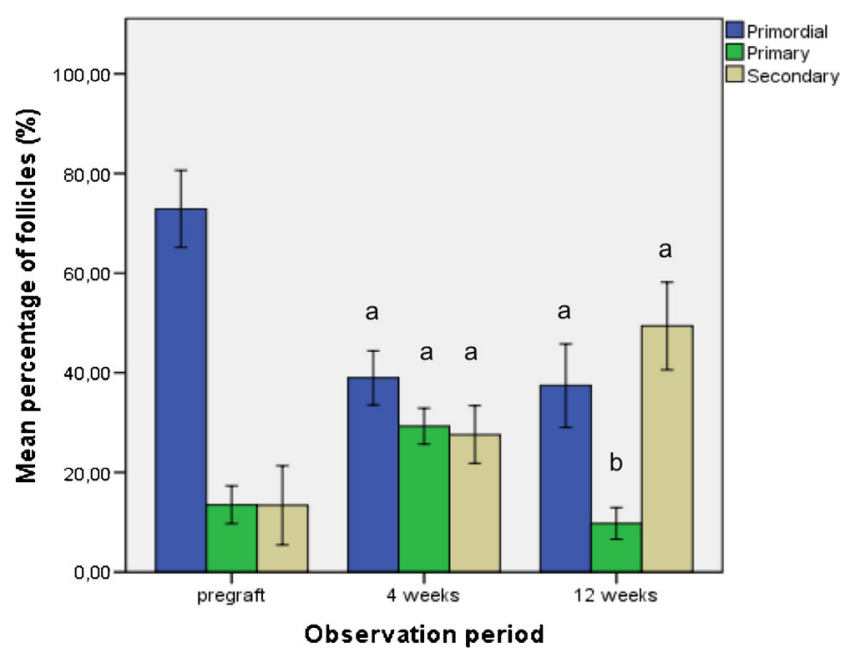

Fig. 1 Follicles were classified and counted in pregraft control, 4-week grafts, and 12-week grafts. Total follicles per biopsy as well as percentages of primordial, primary, and secondary follicles are presented in mean \pm SEM. Antral follicles are not represented in the figure and the table because they formed only $0.49 \%(5 / 1014)$ of all follicles observed. $a$ Significant differences between the two observation periods and pregraft control $(P<0.05) . b$ Significant differences between 4 and 12 weeks of grafting $(P<0.05)$ 
Table 2 Percentage of Ki67 positive follicles in pregraft controls, 4week grafts, and 12-week grafts

\begin{tabular}{llll}
\hline Follicle stage & Pregraft & 4 weeks & 12 weeks \\
\hline Primordial & $10.28 \%$ & $70.83 \%^{\mathrm{a}}$ & $70.59 \%^{\mathrm{a}}$ \\
& $(11 / 107)$ & $(17 / 24)$ & $(12 / 17)$ \\
Primary & $18.18 \%$ & $50 \%$ & $72.73 \%^{\mathrm{a}}$ \\
& $(2 / 11)$ & $(3 / 6)$ & $(8 / 11)$ \\
Secondary & - & $100 \%$ & $100 \%$ \\
& - & $(4 / 4)$ & $(14 / 14)$ \\
Antral & - & - & $100 \%$ \\
& - & - & $(2 / 2)$ \\
Total Ki67 positive follicles & $11.02 \%$ & $70.59 \%^{\mathrm{a}}$ & $81.82 \%{ }^{\mathrm{a}}$ \\
& $(13 / 118)$ & $(24 / 34)$ & $(36 / 44)$ \\
\hline
\end{tabular}

Percentage of primordial, primary, secondary, and antral follicles showing Ki67 immunostaining in pregraft controls and after 4 and 12 weeks of grafting, respectively. The total number of Ki67-positive follicles as well as the total number of all analyzed follicles are given in brackets

${ }^{a}$ Significant difference between the two observation periods compared to the pregraft control $(P<0.05)$

\section{Follicular growth}

A total of 196 follicles from 10 patients were analyzed for Ki67 immunohistochemistry. The percentage of all Ki67-positive follicles after $4(70.59 \%, P<0.001)$ and $12(81.82 \%, P<0.001)$ weeks of grafting was significantly higher compared to pregraft controls (11.02\%). The percentage of Ki67-positive primordial follicles increased from $10.28 \%$ in pregraft controls to $70.83 \%$ after 4 weeks of grafting $(P<0.001)$ and to $70.59 \%$ after 12 weeks of grafting $(P<0.001)$. The percentage of Ki67 positive primary follicles was not significantly higher after 4 weeks of grafting (50\%, $P=0.205)$ compared to pregraft controls $(18.18 \%)$, but it was significantly higher after 12 weeks of grafting $(72.73 \%, P=0.015)$ compared to pregraft controls
$(18.18 \%)$. All detected secondary follicles were Ki67-positive regardless of the observation period. Two antral follicles were found after 12 weeks of grafting and both were Ki67 positive. There was no significant difference in the percentage of Ki67 positive follicles of all stages between 4 and 12 weeks of grafting (Table 2 and supplementary Fig. 2).

\section{Follicular apoptosis}

In order to detect signs of apoptosis, 96 follicles from 9 patients were analyzed. In pregraft controls and after 4 weeks of grafting, none of the follicles were TUNEL positive. After 12 weeks of grafting, one secondary follicle showed one TUNEL-positive granulosa cell (supplementary Fig. 3).

\section{Downregulation of PTEN expression after xenotransplantation of cryopreserved/thawed human ovarian tissue}

\section{PTEN gene expression}

PTEN expression was analyzed in 8 pregraft controls and $114-$ week-grafts obtained from 8 patients. Genomic DNA contamination was negative in all RNA samples. The relative gene expression of PTEN was compared between pregraft controls and 4-week grafts after normalization using actin as the housekeeping gene. The amplification efficiency of qPCR was higher than 1.8 in all measurements. The expression of PTEN was reduced by 2.47-fold after 4 weeks of xenotransplantation (Fig. 2). This result was significant when $2^{-\Delta \mathrm{Ct}}$ were analyzed $(P=0.042)$. There was no significant correlation between the reduced numbers of follicles and PTEN expression as shown in supplementary data (supplementary Fig. 5).
Fig. 2 Relative expression of the PTEN gene after xenotransplantation compared to pregraft control. Figure shows 2.47-fold reduction of the PTEN gene expression after 4 weeks of grafting. This difference reached significance when $2^{-\Delta \mathrm{Ct}}$ were analyzed. Data are presented in mean \pm SEM

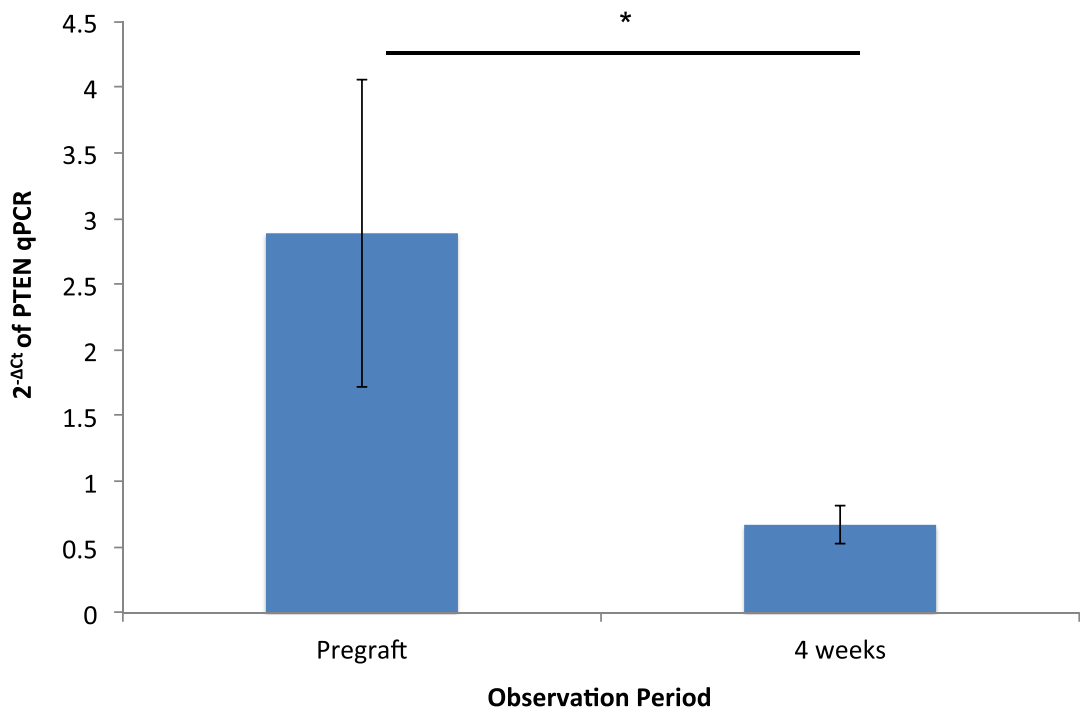




\section{PTEN immunohistochemistry}

PTEN protein expression was detectable in theca cells and granulosa cells from growing follicles, as well as in the nuclei and cytoplasm of all oocytes (supplementary Fig. 6). In granulosa cells of primordial follicles, PTEN protein was either absent or weakly expressed.

\section{Discussion}

This study examines for the first time the molecular mechanisms that may be involved in the increased follicular recruitment after xenotransplantation of cryopreserved/thawed human ovarian tissue. The data, compiled from a considerable number of patients, show that the observed acceleration of follicular growth is most likely due to downregulation of PTEN.

After 4 and 12 weeks of grafting, histological evaluation revealed a pronounced decrease of primordial follicles accompanied by an increase of growing follicles. Only few granulosa cells and none of the oocytes were apoptotic after grafting. In addition, increased follicular recruitment was indicated by the increase of Ki-67-positive primordial and primary follicles after 4 and 12 weeks of xenotransplantation.

A corresponding downregulation of PTEN was detected with qPCR after grafting, without any significant correlation between the reduced numbers of follicles and PTEN expression as shown in supplementary data (supplementary Fig. 5).

PTEN is an important component of the PI3K pathway, which has been described to play a crucial role in follicular recruitment [36]. The deletion of PTEN in mice has been shown to result in premature ovarian failure due to the complete depletion of primordial follicles [39]. In vitro culture studies in human ovarian tissue by Novella-Maestre et al. [54] showed that PTEN inhibition enhances the activation of primordial follicles and increases the population of growing follicles without inducing apoptosis in follicles or in the surrounding stroma. Other in vitro studies by McLaughlin et al. [42] demonstrated that the addition of the PTEN inhibitor bpV(HOpic) alters human ovarian follicular growth by inducing the initiation of primordial follicle recruitment to the secondary stage. Additionally, Li et al. [43] proved that the administration of a PTEN inhibitor bpV(HOpic) and a $\mathrm{PI} 3 \mathrm{~K}$-activating peptide 740Y-P to ovarian tissue could promote follicular development and oocyte maturation.

This ovarian follicle "burnout" caused by dysregulation of the PI3K pathway might be a universal phenomenon [33]. KalichPhilosoph et al. demonstrated the accelerated growth of primordial follicles within $24 \mathrm{~h}$ after cyclophosphamide administration in rodents [34]. In accordance with our study, this was not due to apoptosis, but to activation of the PI3K pathway [34].

Additionally, Silber et al. [20] also observed a massive recruitment of resting follicles after transplantation of cryopreserved/ thawed ovarian tissue shown by increased AMH levels.
Moreover, Silber et al. [55] hypothesized that resting follicles could undergo recruitment after an ovarian tissue fragmentation due to the release from the dense ovarian cortex, which physiologically might arrest follicle recruitment [55-57]. In addition, other studies showed that fragmentation of human ovarian tissue and incubation with Akt stimulators leads to the activation of dormant follicles in patients suffering from premature ovarian insufficiency [14, 19].

In conclusion, to our knowledge, our study confirms these results for the first time in vivo using human ovarian tissue from cancer patients in a xenotransplantation model. Certainly, further studies including shorter observation periods are needed in order to evaluate the starting point of follicular recruitment after xenotransplantation.

In addition, it is essential to investigate additional genes involved in the PI3K pathway, such as Akt, FOXO 3a, and mTOR in human ovarian tissue xenotransplantation. Furthermore, different graft sizes should be evaluated according to previous findings in bovine ovarian tissue.

Overall, the findings of this study might help improve posttransplantational outcomes, as loss of primordial follicles impairs longevity of the grafts after transplantation.

Acknowledgments The authors thank the following members of the Medical University of Innsbruck: Dr. W. Biasio, D. Rosenfellner, L. Horling (Department of Gynecological Endocrinology and Reproductive Medicine), Dr. A. Soleiman (Department of Obstetrics and Gynecology), Prof. H. Dietrich (Central Laboratory Animal Facility), Prof. G. Klima (Division of Histology and Embryology, Department of Anatomy, Histology, and Embryology), and Prof. H. Ulmer (Department of Medical Statistics, Informatics, and Health Economics) and their coworkers for their valuable technical support. The authors thank Dr. R. Kimmel (Institute for Molecular Biology, Innsbruck University) for the assistance with editing the manuscript.

Open access funding provided by University of Innsbruck and Medical University of Innsbruck.

\section{Compliance with ethical standards}

Statement of human rights All procedures performed in studies involving human participants were in accordance with the ethical standards of the institutional and/or national research committee and with the 1964 Helsinki Declaration and its later amendments or comparable ethical standards.

Statement on the welfare of animals All applicable international, national, and/or institutional guidelines for the care and use of animals were followed. All procedures performed in studies involving animals were in accordance with the ethical standards of the institution or practice at which the studies were conducted.

Competing interests The authors declare that they have no conflict of interest.

Study funding This study was funded by the Tyrolean Research Foundation.

S.A. was supported by a scholarship from the Indonesian Directorate General of Higher Education, Ministry of National Education, Indonesia. K.W.-C. was supported by a DOC-fFORTE scholarship from the Austrian Academy of Sciences and the Austrian Federal Ministry of Science and Research. 
Open Access This article is distributed under the terms of the Creative Commons Attribution 4.0 International License (http:// creativecommons.org/licenses/by/4.0/), which permits unrestricted use, distribution, and reproduction in any medium, provided you give appropriate credit to the original author(s) and the source, provide a link to the Creative Commons license, and indicate if changes were made.

\section{References}

1. Gatta G, Botta L, Rossi S, Aareleid T, Bielska-Lasota M, Clavel J, et al. Childhood cancer survival in Europe 1999-2007: results of EUROCARE-5-a population-based study. Lancet Oncol. 2014;15(1):35-47.

2. Roness H, Kalich-Philosoph L, Meirow D. Prevention of chemotherapy-induced ovarian damage: possible roles for hormonal and non-hormonal attenuating agents. Hum Reprod Update. 2014;20(5):759-74.

3. Morgan S, Lopes F, Gourley C, Anderson RA, Spears N. Cisplatin and doxorubicin induce distinct mechanisms of ovarian follicle loss; imatinib provides selective protection only against cisplatin. PLoS ONE. 2013;8(7):e70117.

4. Morgan S, Anderson RA, Gourley C, Wallace WH, Spears N. How do chemotherapeutic agents damage the ovary? Hum Reprod Update. 2012;18(5):525-35.

5. Meirow D, Biederman H, Anderson RA, Wallace WHB. Toxicity of chemotherapy and radiation on female reproduction. Clin Obstet Gynecol. 2010;53(4):727-39.

6. Schmidt KT, Larsen EC, Andersen CY, Andersen AN. Risk of ovarian failure and fertility preserving methods in girls and adolescents with a malignant disease. BJOG. 2010;117(2):163-74.

7. Loren AW, Mangu PB, Beck LN, Brennan L, Magdalinski AJ, Partridge $\mathrm{AH}$, et al. Fertility preservation for patients with cancer: American Society of Clinical Oncology clinical practice guideline update. J Clin Oncol. 2013;31(19):2500-10.

8. Practice Committee of the American Society for Reproductive Medicine. Fertility preservation in patients undergoing gonadotoxic therapy or gonadectomy: a committee opinion. Fertil Steril 2013;100Suppl 5:1214-23.

9. Winkler-Crepaz K, Ayuandari S, Hofer S, Wildt L. Fertility preservation in cancer survivors. Minerva Endocrinol. 2015;40:105-18.

10. De Vos M, Smitz J, Woodruff TK. Fertility preservation in women with cancer. Lancet. 2014;384(9950):1302-10.

11. von Wolff M, Montag M, Dittrich R, Denschlag D, Nawroth F, Lawrenz B. Fertility preservation in women - a practical guide to preservation techniques and therapeutic strategies in breast cancer, Hodgkin's lymphoma and borderline ovarian tumours by the fertility preservation network FertiPROTEKT. Arch Gynecol Obstet. 2011;284(2):427-35.

12. Demeestere I, Simon P, Dedeken L, Moffa F, Tsepelidis S, Brachet C, et al. Live birth after autograft of ovarian tissue cryopreserved during childhood. Hum Reprod. 2015;30:2107-9.

13. Donnez J, Dolmans M-M. Fertility preservation in women. Nat Rev Endocrinol. 2013;9:735-49.

14. Kawamura K, Cheng Y, Suzuki N, Deguchi M, Sato Y, Takae S, et al. Hippo signaling disruption and Akt stimulation of ovarian follicles for infertility treatment. Proc Natl Acad Sci U S A. 2013;110(43):17474-9.

15. Dittrich R, Hackl J, Lotz L, Hoffmann I, Beckmann MW. Pregnancies and live births after 20 transplantations of cryopreserved ovarian tissue in a single center. Fertil Steril. 2014;103:462-8.

16. Rodriguez-Wallberg KA, Karlström P-O, Rezapour M, Castellanos E, Hreinsson J, Rasmussen C, et al. Full-term newborn after repeated ovarian tissue transplants in a patient treated for Ewing sarcoma by sterilizing pelvic irradiation and chemotherapy. Acta Obstet Gynecol Scand. 2015;94:324-8.
17. Stoop D, Cobo A, Silber S. Fertility preservation for age-related fertility decline. Lancet. 2014;384(9950):1311-9.

18. Donnez J, Dolmans M-M. Ovarian cortex transplantation: 60 reported live births brings the success and worldwide expansion of the technique towards routine clinical practice. J Assist Reprod Genet 2015;9-13.

19. Suzuki N, Yoshioka N, Takae S, Sugishita Y, Tamura M, Hashimoto $\mathrm{S}$, et al. Successful fertility preservation following ovarian tissue vitrification in patients with primary ovarian insufficiency. Hum Reprod. 2015;30(6):608-15.

20. Silber S, Pineda J, Lenahan K, DeRosa M, Melnick J. Fresh and cryopreserved ovary transplantation and resting follicle recruitment. Reprod Biomed Online. 2015;30(6):643-50.

21. Silber S, Kagawa N, Kuwayama M, Gosden R. Duration of fertility after fresh and frozen ovary transplantation. Fertil Steril. 2010;94(6):2191-6.

22. Silber SJ. Ovary cryopreservation and transplantation for fertility preservation. Mol Hum Reprod. 2012;18(2):59-67.

23. Donnez J, Dolmans M-M, Pellicer A, Diaz-Garcia C, Sanchez Serrano M, Schmidt KT, et al. Restoration of ovarian activity and pregnancy after transplantation of cryopreserved ovarian tissue: a review of 60 cases of reimplantation. Fertil Steril. 2013;99(6): 1503-13.

24. Donnez J, Dolmans M-M, Diaz C, Pellicer A. Ovarian cortex transplantation: time to move on from experimental studies to open clinical application. Fertil Steril. 2015;104(5):1097-8.

25. Meirow D, Levron J, Eldar-Geva T, Hardan I, Fridman E, Yemini Z, et al. Monitoring the ovaries after autotransplantation of cryopreserved ovarian tissue: endocrine studies, in vitro fertilization cycles, and live birth. Fertil Steril. 2007;87(2):418.e7-.e15.

26. Greve T, Schmidt KT, Kristensen SG, Ernst E, Andersen CY. Evaluation of the ovarian reserve in women transplanted with frozen and thawed ovarian cortical tissue. Fertil Steril. 2012;97(6): 1394-8.e1.

27. Janse F, Donnez J, Anckaert E, de Jong FH, Fauser BCJM, Dolmans M-M. Limited value of ovarian function markers following orthotopic transplantation of ovarian tissue after gonadotoxic treatment. J Clin Endocrinol Metab. 2011;96(4):1136-44.

28. Gook DA, Edgar DH, Borg J, Archer J, McBain JC. Diagnostic assessment of the developmental potential of human cryopreserved ovarian tissue from multiple patients using xenografting. Hum Reprod. 2005;20(1):72-8.

29. Amorim CA, David A, Dolmans M-M, Camboni A, Donnez J, Van Langendonckt A. Impact of freezing and thawing of human ovarian tissue on follicular growth after long-term xenotransplantation. J Assist Reprod Genet. 2011;28(12):1157-65.

30. Schubert B, Canis M, Darcha C, Artonne C, Smitz J, Grizard G. Follicular growth and estradiol follow-up after subcutaneous xenografting of fresh and cryopreserved human ovarian tissue. Fertil Steril. 2008;89(6):1787-94.

31. Maltaris T, Beckmann MW, Mueller A, Hoffmann I, Kohl J, Dittrich R. Significant loss of primordial follicles after prolonged gonadotropin stimulation in xenografts of cryopreserved human ovarian tissue in severe combined immunodeficient mice. Fertil Steril. 2007;87(1):195-7.

32. Dolmans M-M, Martinez-Madrid B, Gadisseux E, Guiot Y, Yuan WY, Torre A, et al. Short-term transplantation of isolated human ovarian follicles and cortical tissue into nude mice. Reproduction. 2007;134(2):253-62.

33. Roness H, Gavish Z, Cohen Y, Meirow D. Ovarian follicle burnout: a universal phenomenon? Cell Cycle. 2013;12(20):3245-6.

34. Kalich-Philosoph L, Roness H, Carmely A, Fishel-Bartal M, Ligumsky H, Paglin S, et al. Cyclophosphamide triggers follicle activation and "burnout"; AS101 prevents follicle loss and preserves fertility. Sci Transl Med. 2013;5(185):185ra62. 
35. Gavish Z, Peer G, Hadassa R, Yoram C, Meirow D. Follicle activation and "burn-out" contribute to post-transplantation follicle loss in ovarian tissue grafts: the effect of graft thickness. Hum Reprod. 2014;29(5):989-96.

36. Reddy P, Zheng W, Liu K. Mechanisms maintaining the dormancy and survival of mammalian primordial follicles. Trends Endocrinol Metab. 2010;21(2):96-103.

37. Liu K, Rajareddy S, Liu L, Jagarlamudi K, Boman K, Selstam G, et al. Control of mammalian oocyte growth and early follicular development by the oocyte PI3 kinase pathway: new roles for an old timer. Dev Biol. 2006;299(1):1-11.

38. Reddy P, Adhikari D, Zheng W, Liang S, Hämäläinen T, Tohonen $\mathrm{V}$, et al. PDK1 signaling in oocytes controls reproductive aging and lifespan by manipulating the survival of primordial follicles. Hum Mol Genet. 2009;18(15):2813-24.

39. Reddy P, Liu L, Adhikari D, Jagarlamudi K, Rajareddy S, Shen Y, et al. Oocyte-specific deletion of Pten causes premature activation of the primordial follicle pool. Science. 2008;319(5863):611-3.

40. Jagarlamudi K, Liu L, Adhikari D, Reddy P, Idahl A, Ottander U, et al. Oocyte-specific deletion of Pten in mice reveals a stagespecific function of PTEN/PI3K signaling in oocytes in controlling follicular activation. PLoS ONE. 2009;4(7):e6186.

41. Adhikari D, Gorre N, Risal S, Zhao Z, Zhang H, Shen Y, et al. The safe use of a PTEN inhibitor for the activation of dormant mouse primordial follicles and generation of fertilizable eggs. PLoS ONE. 2012;7(6):1-7.

42. McLaughlin M, Kinnell HL, Anderson RA, Telfer EE. Inhibition of phosphatase and tensin homologue (PTEN) in human ovary in vitro results in increased activation of primordial follicles but compromises development of growing follicles. Mol Hum Reprod. 2014;20(8):736- 44 .

43. Li J, Kawamura K, Cheng Y, Liu S, Klein C, Liu S, et al. Activation of dormant ovarian follicles to generate mature eggs. Proc Natl Acad Sci U S A. 2010;107(22):10280-4.

44. Oberhuber R, Ritschl P, Fabritius C, Nguyen A-V, Hermann M, Obrist $\mathrm{P}$, et al. Treatment with tetrahydrobiopterin overcomes brain death-associated injury in a murine model of pancreas transplantation. Am J Transplant. 2015. doi:10.1111/ajt13364.

45. Lotz L, Schneider H, Hackl J, Wachter D, Hoffmann I, Jurgons R, et al. Does stimulation with human gonadotropins and gonadotropin-releasing hormone agonist enhance and accelerate the developmental capacity of oocytes in human ovarian tissue xenografted into severe combined immunodeficient mice? Fertil Steril. 2014;101(5):1477-84.
46. Myers M, Britt KL, Wreford NGM, Ebling FJP, Kerr JB. Methods for quantifying follicular numbers within the mouse ovary. Reproduction. 2004;127(5):569-80.

47. Winkler-Crepaz K, Nederegger V, Ayuandari S, Rosenfellner D, Zervomanolakis I, Hofer S, et al. Novel dynamic culture system to support initiation of primordial follicle growth in prepubertal mouse ovaries. Fertil Steril. 2014;102(3):864-70.e2.

48. Amorim CA, Jacobs S, Devireddy RV, Van Langendonckt A, Vanacker $\mathrm{J}$, Jaeger J, et al. Successful vitrification and autografting of baboon (Papio anubis) ovarian tissue. Hum Reprod. 2013;28(8):2146-56.

49. Amorim CA, Dolmans M-M, David A, Jaeger J, Vanacker J, Camboni A, et al. Vitrification and xenografting of human ovarian tissue. Fertil Steril. 2012;98(5):1291-8.e1-2.

50. Goto M, Iwase A, Harata T, Takigawa S, Suzuki K, Manabe S, et al. IGF1-induced AKT phosphorylation and cell proliferation are suppressed with the increase in PTEN during luteinization in human granulosa cells. Reproduction 2004;10.

51. 51. Ruijter JM, Lorenz P, Tuomi JM, Hecker M, Hoff MJB Van Den. Fluorescent-increase kinetics of different fluorescent reporters used for qPCR depend on monitoring chemistry, targeted sequence, type of DNA input and PCR efficiency. Mikrochim Acta 2014;1689-96.

52. Pabinger S, Rödiger S, Kriegner A, Vierlinger K, Weinhäusel A. Biomolecular detection and quantification a survey of tools for the analysis of quantitative PCR (qPCR) data. Biomol Detect Quantif. 2014;1(1):23-33.

53. Schmittgen TD, Livak KJ. Analyzing real-time PCR data by the comparative C T method. Nat Protoc. 2008;3(6):1101-8.

54. Novella-Maestre E, Herraiz S, Rodríguez-Iglesias B, Díaz-García C, Pellicer A. Short-term PTEN inhibition improves in vitro activation of primordial follicles, preserves follicular viability, and restores AMH levels in cryopreserved ovarian tissue from cancer patients. PLoS ONE. 2015;10(5):e0127786.

55. Silber S. Unifying theory of adult resting follicle recruitment and fetal oocyte arrest. Reprod Biomed Online. 2015;31(4): $472-5$.

56. Shikanov A, Smith RM, Xu M, Woodruff TK, Shea LD. Hydrogel network design using multifunctional macromers to coordinate tissue maturation in ovarian follicle culture. Biomaterials. 2011;32(10):2524 31.

57. Woodruff TK, Shea LD. A new hypothesis regarding ovarian follicle development: ovarian rigidity as a regulator of selection and health. J Assist Reprod Genet. 2011;28(1):3-6. 